\title{
Crowd Dispersal in Staircase Design for Multi-Storey Building
}

${ }^{* 1}$ Nurul Liyana Hanapi, ${ }^{2}$ Sabarinah Sheikh Ahmad, ${ }^{3}$ Azli Abd Razak

${ }^{1}$ Centre of Building and Resilient Development, Faculty of Engineering, Built Environment \& IT, SEGI University

${ }^{2}$ Faculty of Architecture, Planning and Surveying, Universiti Teknologi MARA (UiTM)

${ }^{3}$ Faculty of Mechanical Engineering, Universiti Teknologi MARA (UiTM)

* liyanahanapi@segi.edu.my

\begin{abstract}
Staircase evacuation has always been a popular topic as today's buildings are mostly dependent on the staircase for vertical transportation. This paper discussed the effect of open staircase position and width towards evacuation duration and distance. To simulate a real emergency situation, an experimental study needed to be conducted by using pathfinder software. Results show that increasing escape route width improves evacuation duration but the distance is much influence based on the positioning of the staircase in the building. The different staircase scenario has a significant influence on crowd dispersal. Future study can focus on various speed of the occupant to see how it will influence the crowd dispersal in a multi-storey building
\end{abstract}

Keywords: Crowd Dispersal, Emergency, Multi-Storey, Elderly, Evacuation

\section{Introduction}

Almost all buildings are bounded with the safety requirement set by the authorities. During the design stage, the passenger evacuation capacity is calculated based on the requirement set by the authorities that consist of ventilation, exit, and staircase design. Although the fire safety design procedure has been implemented in the building, the insufficient number of egress could create the bottleneck issue (Shen et al. 2018; Lawson, 2011; 
Zhang, 2017). The designer might provide adequate egress choices for the evacuation process based on the population of the occupants in a building period. But the increased number of the occupants and the guideline that only cater to the speed of people, in general, might result in the capability of the escape route design to be insufficient.

Staircases have become one of the most important means of escape in multi-storey buildings. The number of staircases determines the efficiency of an evacuation process. Nowadays, having a single staircase in a multi-storey building is insufficient; if the staircase catches on fire, there is simply no other means to transport occupants to safety.

That explains why the new regulation has made it compulsory for every high-rise building to have a minimum of two (2) staircases. According to the UBBL 1984 (Amendment 2012), designers are required to provide additional staircases that are able to serve the same flow rate as the provision of one staircase is insufficient

There are opinions that increasing the number of staircases and widening evacuation passageways may reduce evacuation time. However, no clear explanation on the appropriate number of staircases and passageway width to be used have been stated (Jiang et al.; 2011, Noh et al,; 2016, Sticco et al.; 2017). Thus, this paper will advise the appropriate widths of escape routes to be used to contribute towards evacuation efficiency and how the staircase positioning are heavily influence the crowd dispersal in the building.

\section{Materials and methods}

Since the existing safety facilities in Malaysia are limited to the requirement set by the UBBL 1984 and cost constraint, it is not viably to introduce new escape route provision. This paper simulate the existing typical building typology that has been used in Malaysia which is the public housing. Thus, only enhancement to the existing escape route provision were considered without making vast changes on the overall planning as it will change the layout which will influence the overall cost of the public housing development. 
Figure 1 shows the current typical layout of the public housing used in Malaysia where the arrangement of the building is linear with three numbers of naturally ventilated staircases which connected by a single loading corridors. Besides conforming the given layout of the building, the size of every spaces in a house is also specified where designer are to abide to the minimum size of every component that has been detailed together with the overall design layout. All requirements mentioned make up the basic standard which helps reduce the duration of building planning and ensures fast approval, which in turn reduces and minimises the cost and duration of construction.

The base case model used in this study is the linear building layout configuration for public buildings. The building was tested using the agentbased approach as elderly evacuees, and adult evacuees with various walking speeds were included in this simulation study. The simulation was carried out using Pathfinder, an evacuation software, to evaluate the speed and movement of evacuees. The building model, which was first drawn using AutoCAD and Sketchup, was imported to PathFinder. Figure 1 is the base case layout plan of public buildings introduced to the PathFinder software.

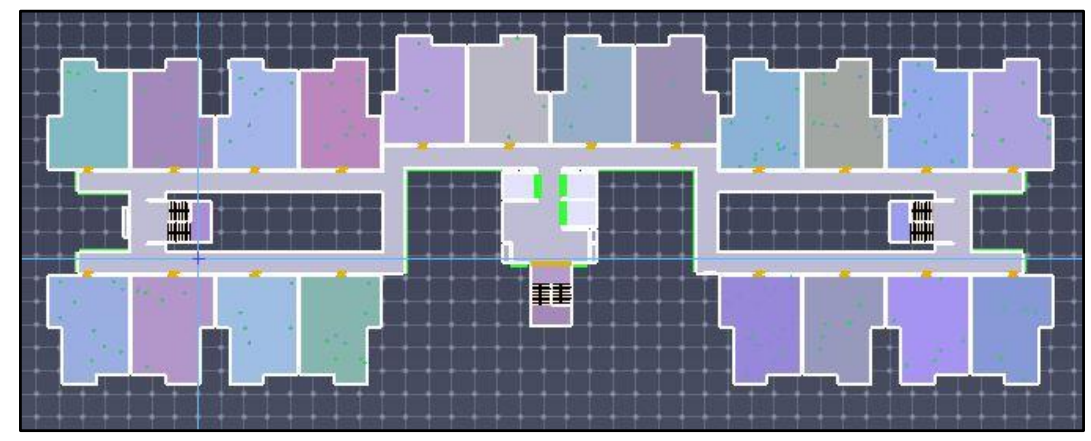

Figure 1. Current typical layout of public housing in Malaysia

Since the study focuses more on finding the optimum escape route dimension could minimise the duration of evacuation time, the study conducts test based on the actual dimension. The escape route width however was increased little by little until the data were rich. The actual dimension of the escape route width was $1200 \mathrm{~mm}$, it was then increased by $300 \mathrm{~mm}$ as in normal practice. So, in this study, the escape route width dimensions tested were 1 
$300 \mathrm{~mm}$ (actual size), $1500 \mathrm{~mm}$, and $1800 \mathrm{~mm}$. This section unveils the effect of the number and availability of staircases for usage during the evacuation process. The model used in this simulation study was a Malaysian public housing as three (3) staircases are normally provided to cater to the high number of occupants. Three (3) different cases as shown in Table 2 were tested.

Table 1. The conditions of the three staircases in the three cases

\begin{tabular}{ll}
\hline Cases & Title \\
\hline Case 1 & All three staircases are open and can be used \\
\hline Case 2 & $\begin{array}{l}\text { Centre staircase is closed and only side staircase can } \\
\text { be used }\end{array}$ \\
\hline Case 3 & $\begin{array}{l}\text { One side staircase is closed while the centre and other } \\
\text { side staircase are available }\end{array}$ \\
\hline
\end{tabular}

Since the left and right staircases are identical, only one side representing both was tested. While doing so, the total occupancy and percentage of elderly evacuees were also considered. The distributions used in the different scenarios are shown in Table 2. Low density occupancy is calculated based on 4 person per household which take up to 1478 occupancy in one simulation test. Medium and high density both are calculated based on 5 to 6 person per household which take up to 1700 and 2100 occupancy in one simulation test.

Table 2. Simulation test based on different occupant variables.

\begin{tabular}{|c|c|c|c|c|}
\hline Section & Code & Number of occupants & $\begin{array}{l}\text { Percentage of } \\
\text { elderlies }\end{array}$ & $\begin{array}{l}\text { Percentage of } \\
\text { adults }\end{array}$ \\
\hline \multirow{3}{*}{ A } & A1 & 1478 & \multirow{3}{*}{$0 \%$ of elderlies } & \multirow{3}{*}{$100 \%$ adults } \\
\hline & $\mathrm{A} 2$ & 1700 & & \\
\hline & A3 & 2100 & & \\
\hline \multirow{3}{*}{ B } & B1 & 1478 & \multirow{3}{*}{$7 \%$ of elderlies } & \multirow{3}{*}{$93 \%$ of adults } \\
\hline & $\mathrm{B} 2$ & 1700 & & \\
\hline & B3 & 2100 & & \\
\hline \multirow{3}{*}{$\mathrm{C}$} & $\mathrm{C} 1$ & 1478 & \multirow{3}{*}{$10 \%$ of elderlies } & \multirow{3}{*}{$90 \%$ of adults } \\
\hline & $\mathrm{C} 2$ & 1700 & & \\
\hline & C3 & 2100 & & \\
\hline $\mathrm{D}$ & D1 & 1478 & $15 \%$ of elderlies & $85 \%$ of adults \\
\hline
\end{tabular}




\begin{tabular}{ll} 
D2 & 1700 \\
\hline D3 & 2100
\end{tabular}

\section{Results and discussion}

\subsection{Maximum evacuation time}

Figure 2 shows the maximum evacuation time obtained from the three cases experimenting on escape route width dimensions of $1300 \mathrm{~mm}, 1500 \mathrm{~mm}$ and $1800 \mathrm{~mm}$. The longest maximum evacuation time of 737 seconds was recorded in case 3 (in which one side staircase was closed) with an escape route width of $1300 \mathrm{~mm}$. High occupancy and the presence of elderly evacuees with the narrowest escape route width $(1300 \mathrm{~mm})$ were found to result in longer evacuation time. This proves that the highest occupancy level recorded the longest evacuation time (refer to green line). The shortest evacuation time of 285 seconds was recorded in case 1 (all staircases were open) with an escape route of $1800 \mathrm{~mm}$ width. High availability of staircases together with small occupancy level and exclusion of elderly evacuees were indicated to lead to faster evacuation time. This is shown in case 1 (refer to blue line).

Based on the values obtained, the overall results show that the number of staircases is a huge factor in determining total evacuation time. Figure 2 shows case 1 recording the shortest evacuation time in comparison with cases 2 and 3. Case 1 was provided with more staircases, thus enabling the occupant rate for each staircase to be reduced. This thereby proves that evacuation time increases as the number of staircases decreases.

Looking at the same figures, it can also be noted that there was not much difference in the evacuation time recorded in cases 2 and 3. This henceforth indicates that the location of staircases did not cause a huge impact on total evacuation time. This means that although there was a slight difference between cases 2 and 3 in terms of results, the difference was very minimal.

Figure 2 shows the graphs in different colours, indicating the various numbers of occupancy. The blue represents 1478 people; the orange represents 1700 people; and the green represents 2040 people. The number people were determined based on the number of people per household. From the figure, it 
can clearly be seen that the higher the occupancy density was, the longer it took for people to safely evacuate the building. This data supports the findings of a study by Chunmiao et al. (2012) which claimed to have found a linear relationship between population and evacuation time.

Figure 2 also shows that increasing the escape route width reduces the overall evacuation time. The result is nonetheless only applicable if all escape route types are of the same width. From the figure and the comparison of graphs using different colours, it can also be observed that evacuation time increases as the percentage of elderly evacuee's increases. Data in Figure 2 also show results for the experiments on overall occupancy and the comparison made between elderly evacuees and adults.

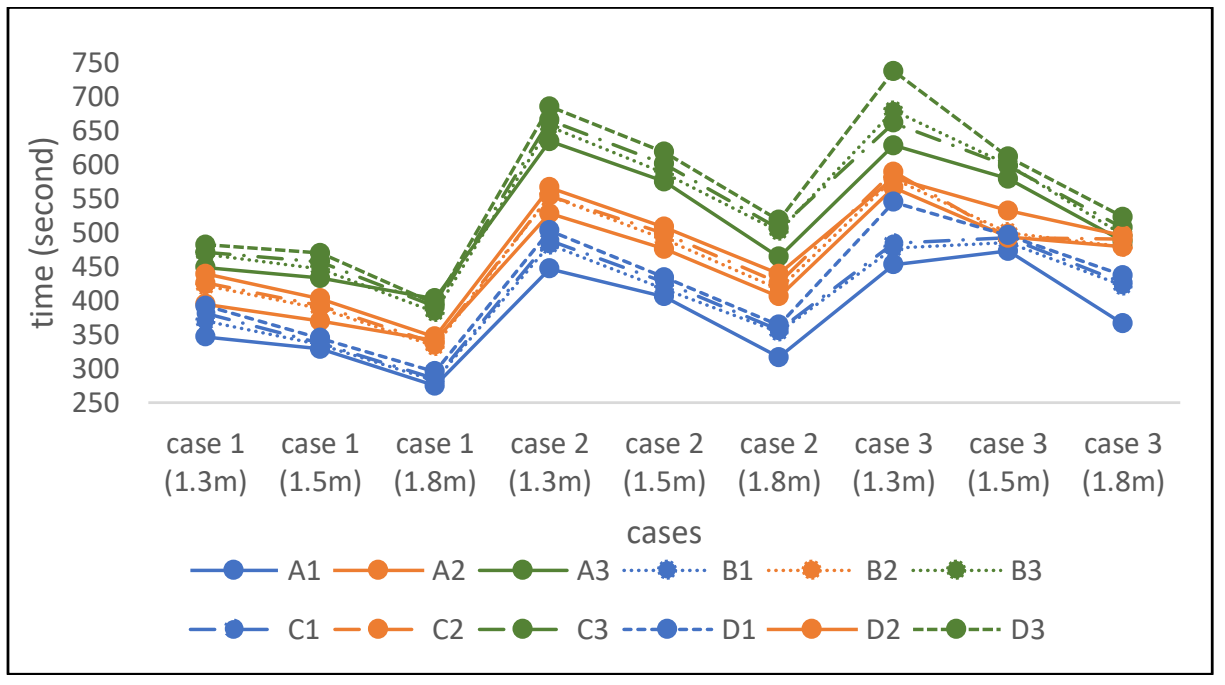

Figure 2. Maximum evacuation time obtained from the three different escape route widths in relation with the different staircase conditions

\subsection{Mean evacuation time}

Figure 3 presents the mean (average) evacuation time recorded in the various staircase scenarios. Case 1 with an escape route width of $1800 \mathrm{~mm}$ recorded the shortest mean evacuation time of 135 seconds, whereas the highest (324 seconds) mean evacuation time was observed in case 3 in which the escape route width was the smallest. Despite the faster evacuation times 
recorded in case 3 , case 2 (with $1300 \mathrm{~mm}$ escape route) also showed similar results with only 1 second difference. Based on the data provided, it can hence be stipulated that the mean evacuation times of cases 2 and 3 were very similar.

Even though the results show a slightly longer mean evacuation time for case 3, all occupants from case 2 and 3 on average had evacuated within the same time. This was due to the fact that both cases were provided with the same number of staircases, thus producing the same flow rates that subsequently created the same average evacuation time. This verifies that the location of staircase did not determine evacuation time.

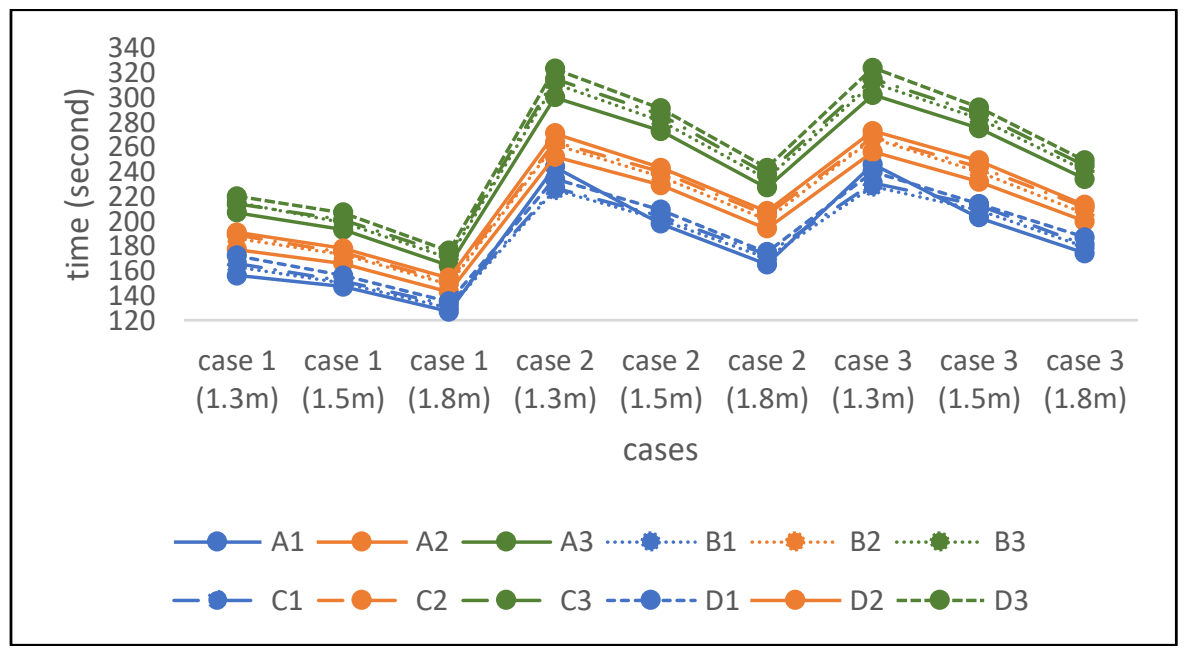

Figure 3. Mean evacuation time of the different staircase scenarios

\subsection{Maximum travel distance}

Time is crucial in determining evacuation efficiency from a building. This is because longer evacuation time will expose occupants to greater risks. Although many studies have focused on the duration of evacuation, many researchers did not put an emphasis on evacuees' total travel distance upon getting to safety. Especially in multi-storey residential housing, occupants need to travel bigger distances to get to safety; this hence impose greater risks on occupants. This is due to the fact that energy decreases as one travels longer distances. High stagnation at exits which can possibly cause people to make U-turns also stretches the total distance travelled during an evacuation. 
This can be an issue for elderly evacuees as they tend to get tired fast, especially after a lot of physical movements as their physique has started to deteriorate. Thus, it is important to understand the effect of escape route changes on the total distance to be travelled. This section elaborates on the side effect of the number of staircases on the total distance evacuees had to travel to get to safety

The travel distance in this section is referring to the total distance travel from the starting point up until the evacuees able to evacuate out of the building. Figure 4 shows the maximum travel distance for all three staircase scenarios. The maximum travel distances with three escape route widths in case 1 show similar results regardless of the variables involved. This indicates that the total number of population, its percentage of elders and escape route width did not significantly contribute to travel distance when all staircases were made available. As for cases 2 and 3 in which one staircase was either closed or deemed unusable, larger increments in the maximum travel distance of occupants were observed.

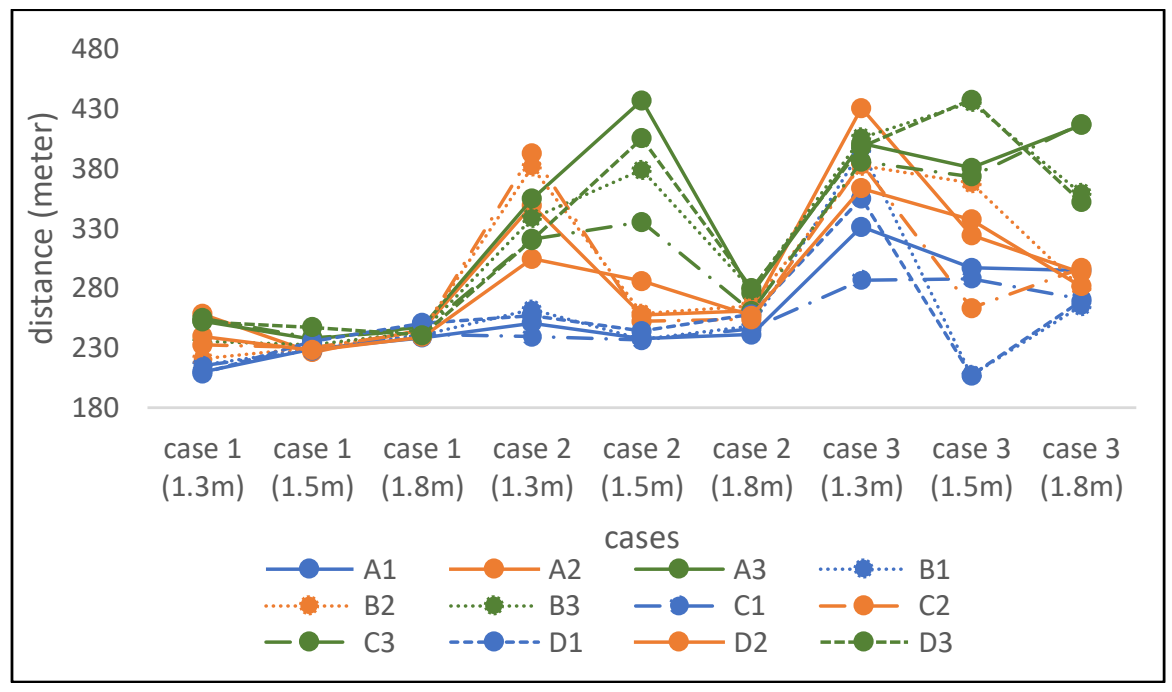

Figure 4. Maximum travel distance of the different staircase scenarios.

The longest travel distances from the starting point until the point of safety were $437.2 \mathrm{~m}$ and $436.6 \mathrm{~m}$ found in case 3 (with an escape route of $1500 \mathrm{~mm}$ 
width) and case 2 (with an escape route of $1500 \mathrm{~mm}$ width), respectively. It is to be pointed out that both cases with the same escape route width recorded the highest travelling distances were actually accompanied with the highest occupancy level and highest percentage of elderly evacuees. The shortest distance was recorded in case 3 with an escape route width of $1500 \mathrm{~mm}$. The case with the lowest occupancy level and highest percentage of elderly evacuees recorded a travel distance of $207.1 \mathrm{~m}$. A distance of $206.8 \mathrm{~m}$ was recorded in a similar case with the lowest occupancy level and $7 \%$ of elderly occupants.

The actual dimension of escape routes in PPR buildings is $1300 \mathrm{~mm}$ wide. Increments in the dimension of escape route did not change the maximum travel distance. To illustrate, in case 2, while the travel distance was found to increase as the escape route was increased to $1500 \mathrm{~mm}$; travel distance was observed to significantly decrease as the width was increased to $1800 \mathrm{~mm}$. As for case 3 , distance was found to decrease as width increased.

When comparing cases 2 and 3 with an escape route width of $1800 \mathrm{~mm}$, case 2 with the centre staircase being closed and an equal distribution of staircases was found to record the highest travel distance as occupants had to resort to side staircases. As a result, the number of staircases plays a considerable factor in determining the maximum travel distance of occupants. Having even one closed staircase could create stagnation at the staircase area, forcing evacuees to find other means of escape which then results in a longer travel distance. These results were based on the time when the last individual safely evacuates the building, indicating that the person was initially located on the highest floor.

\subsection{Mean travel distance}

Figure 5 shows the mean travel distance of the three cases with three different staircase scenarios. Based on the graph, case 1 (all staircases were available and usable) was denoted to have the lowest average travel distance. As the number of staircases was reduced, the average travel distance increased. Case 3 (side staircase was closed) had the highest average distance. Nonetheless, the results from all three escape route dimensions were almost 
the same. Although case 2 has the same number of staircases with case 3, the mean travel distance recorded was much lower as the closing of the centre staircase equally divided and distributed the evacuees.

This nonetheless did not occur in case 3 in which a side staircase was closed. The closing of a side staircase caused evacuee distribution to heavily depend on the centre staircase, creating a huge stagnation that forced other evacuees to seek other alternative escape routes. The movement of evacuees will be discussed further using recorded simulation images. These results, hoiwever, indicate that the location of staircase plays a considerate factor in determining travel distance. The number of available staircases however did not influence the travel distance of evacuees

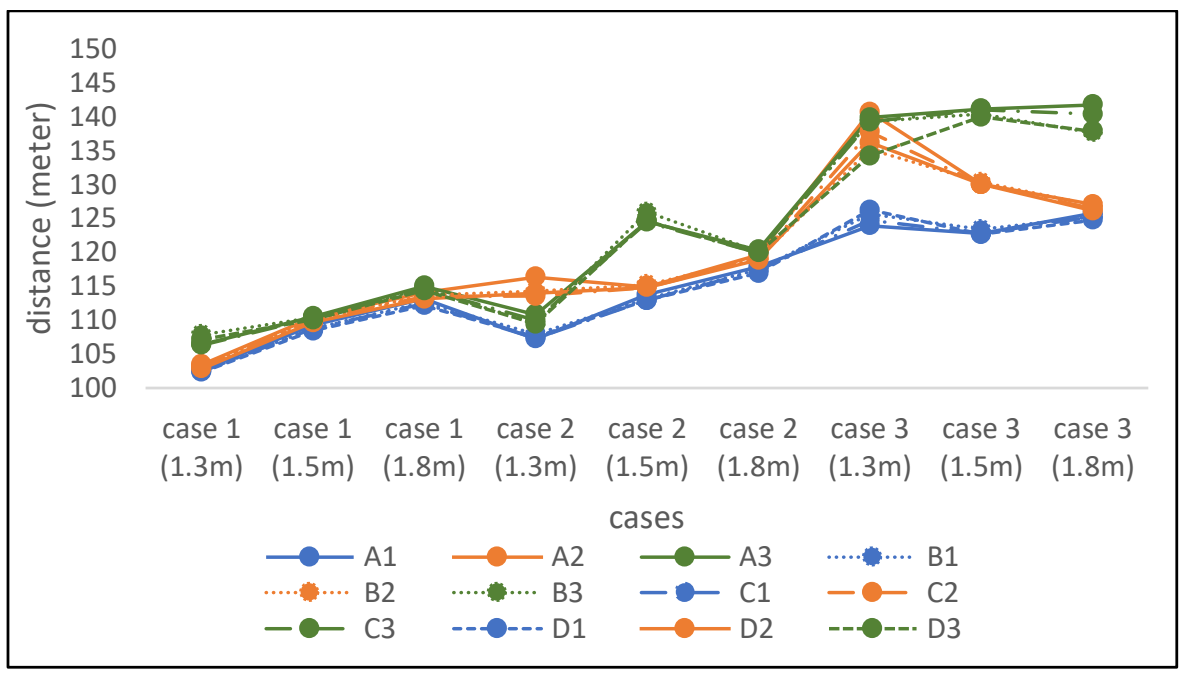

Figure 5. Mean travel distance of the different staircase scenarios

\section{Discussion}

Several findings were drawn from the occupants travelling in the three different staircase scenarios. They are as follows:

1. Evacuees tend to walk further when the number of staircases is reduced; this was due to them turning back and forth between the available staircases.

2. Evacuees nearest to closed or unavailable staircases are required to travel further to find other available means of escape. 
3. Closed side staircases have been proven to force evacuees to travel much further due to the unequal dispersal of crowd in the building.

4. In the case of stagnation, adults' faster speed allowed them to access other means of escape, resulting in them to walk longer distances than the elderly evacuees.

It can be concluded that the number of staircases significantly contributed to evacuation time and travel distance. The location of closed staircases however was not a significant factor determining evacuation time; it nonetheless determined occupants' travel distance as they were required to travel farther when side staircases were closed compared to the closure of centre staircases.

Even though the $1800 \mathrm{~mm}$ escape route width was ranked the highest, statistical data proved that the escape route of $1500 \mathrm{~mm}$ width has a more positive relationship between the time and distance taken by evacuees to get to safety. This paper had focused on the staircase evacuation in multi-storey building but only limited to two set of evacuees. To propose potential future research areas study focusing on variance speed of evacuees consisting of the elderly, adults, children and disable can be conducted.

\section{Acknowledgement}

This study is supported by the Ministry of Education under the Mybrain15 scholarship award and funded by SEGi University Sdn. Bhd. Special thanks to Thunderhead Engineering for providing free license for the Pathfinder softwar

\section{References}

Chunmiao, Y., Chang, L., Gang, L., \& Peihong, Z. (2012). Safety evacuation in building engineering design by using Building Exodus. Systems Engineering Procedia, 5, 87-92.

Jiang Z. A., Chen M. L., \& Wen X. H. (2011). Experiment and simulation study on high-rise student apartment fire personal evacuation in the campus. Procedia engineering, 11,156-161.

Liao, W., Zheng, X., Cheng, L., Zhao, Y., Cheng, Y., \& Wang, Y. (2014). Layout effects of multi-exit ticket-inspectors on pedestrian evacuation. Safety science, 70, 1-8. 
Noh, D. J., Koo, J., \& Kim, B. I. (2016). An efficient partially dedicated strategy for evacuation of a heterogeneous population. Simulation Modelling Practice and Theory, 62, 157-165.

UBBL, U. (2013). Laws of Malaysia (Act 133): Uniform Building By-Law 1984 (UBBL). Department, LG (ed.) Sixteenth Edition ed. Kuala Lumpur: MDC Publishers Sdn Bhd.

Shen, J. Q., Wang, X. W., \& Jiang, L. L. (2018). The influence of panic on the efficiency of escape. Physica A: Statistical Mechanics and Its Applications, 491, 613-618. Sticco, I. M., Frank, G. A., Cerrotta, S., \& Dorso, C. O. (2017). Room evacuation through two

contiguous exits. Physica A: Statistical Mechanics and its Applications, 474, $172-185$.

Tan, L., Hu, M., \& Lin, H. (2015). Agent-based simulation of building evacuation: Combining human behavior with predictable spatial accessibility in a fire emergency. Information Sciences, 295, 53-66.

Varas, A., Cornejo, M. D., Mainemer, D., Toledo, B., Rogan, J., Munoz, V., \& Valdivia, J. A. (2007). Cellular automaton model for evacuation process with obstacles. Physica A:Statistical Mechanics and its Applications, 382(2), 631-642.

Xu, X., \& Song, W. (2009). Staircase evacuation modeling and its comparison with an egress drill. Building and Environment, 44(5), 1039-1046.

Zhang, X. (2017). Study on rapid evacuation in high-rise buildings. Engineering science and technology, an international journal, 20(3), 1203-1210 